07

\title{
Экспериментальный и численный анализ высокоскоростной деформации и эрозионного разрушения титанового сплава ВТ-6
}

\author{
() Ю.В. Петров ${ }^{1,2}$, А.М. Брагов ${ }^{3}$, Н.А. Казаринов ${ }^{2}$, А.Д. Евстифееев ${ }^{2,9}$ \\ ${ }^{1}$ Институт проблем машиноведения РАН, \\ Санкт-Петербург, Россия \\ ${ }^{2}$ Санкт-Петербургский государственный университет, \\ Санкт-Петербург, Россия \\ ${ }^{3}$ Научно-исследовательский институт механики \\ Нижегородского государственного университета им. Н.И. Лобачевского, \\ Нижний Новгород, Россия \\ ฯ E-mail: ad.evstifeev@gmail.com
}

(Поступила в Редакцию 24 мая 2016 г.)

\begin{abstract}
Проведено исследование временных характеристик динамического разрушения титанового сплава ВТ-6 в условиях высокоскоростных нагрузок. Установлена взаимосвязь процесса динамического растяжения образца по методике Кольского и эрозионного повреждения поверхности. Проведен численный анализ экспериментальных данных. Предложено дальнейшее развитие метода эрозионного воздействия как способа динамического тестирования прочностных свойств материалов.
\end{abstract}

Работа выполнена при финансовой поддержке РФФИ (16-31-60003 мол_а_дк, 16-31-60047 мол_а_дк, 16-51-53077), СПбГУ (проект 6.39.319.2014), Минобрнауки России (грант Правительства РФ 14.В25.31.0017).

DOI: 10.21883/FTT.2017.01.43956.214

\section{1. Введение}

Надежность и эффективность современного оборудования, работающего в условиях высокоскоростных динамических нагрузок, в значительной степени зависит от полноты и качества проведенных экспериментальных исследований во всем диапазоне изменения параметров внешнего воздействия. Одной из актуальных проблем экспериментальной механики деформируемого твердого тела является исследование закономерностей поведения материалов различной физической природы в широком диапазоне изменения температур, скоростей деформации и амплитуд нагрузок. Особое место в подобных исследованиях отводится вопросу влияния скорости деформации и истории ее изменения на физикомеханические свойства материалов при скоростях деформации $10^{2}-10^{5} \mathrm{~s}^{-1}$. В настоящее время одним из перспективных методов исследования в этой области является метод с использованием разрезных стержней Гопкинсона (РСГ) и его модификаций $[1,2]$. Другое направление исследований, но не менее важное, может быть направлено на изучение поверхностных свойств материалов в условиях эрозионных испытаний $[3,4]$. Эрозионное воздействие также является динамическим процессом, так как характерное время контакта частицы с поверхностью образца является очень малой величиной, связанной со временем прохода упругой волны по частице. Для изучения такого рода процессов следует применять методы и критерии динамической механики разрушения [5]. При этом важнейшим аспектом исследования эрозионного воздействия на материал является определение различных пороговых характеристик про- цесса, например, пороговой скорости абразивных частиц в потоке.

Исследование пороговых характеристик параметров разрушения (критические скорости, амплитуды, длительности, энергия) позволяют выявить структурновременные особенности процесса и соответствующие им эффекты [6,7].

Исследуемый в настоящей работе материал хорошо себя зарекомендовал и широко используется в конструкциях летательных аппаратов, турбинных двигателей и т.д. При этом современные технологии позволяют существенно улучшить эксплуатационные свойства практически любого материала. Примером такой технологии может служить метод интенсивной пластической деформации (ИПД). Этот метод является предметом исследований многочисленных групп ученых на протяжении последних десятилетий [8]. Изучено влияние уменьшения характерного размера структуры материала на такие его свойства, как статическая и динамическая прочность [9]. В продолжении работы планируется сравнить характеристики прочности и эрозионной стойкости титанового сплава в состоянии поставки и подвергнутого ИПД.

В данной работе теоретически и экспериментально были исследованы прочностные свойства титанового сплава ВТ6 при различных вариациях динамических нагрузок. Было проведено две серии эрозионных нагружений с разными скоростями потока частиц. Выполнена серия экспериментальных исследований по методике Кольского на растяжение. Полученные результаты позволили исследовать зависимость процессов эрозионного деформирования поверхности и высокоскоростного динамического растяжения образцов. 


\section{2. Методика экспериментальных исследований}

Динамические испытания на растяжение были выполнены в НИИ механики ННГУ. Использовалась экспериментальная установка, реализующая метод РСГ, которая включает в себя два пневматических нагружающих устройства, комплекс измерительно-регистрирующей аппаратуры и сменные комплекты разрезных стержней Гопкинсона диаметром 10 и $20 \mathrm{~mm}$. Для производства выстрела сжатый воздух нагнетается компрессором в камеру пушки по магистралям с вентилями. Давление воздуха контролируется манометром. После достижения требуемого давления срабатывает электромагнитный пневмоклапан и сжатый воздух попадает в спусковую камеру пушки. Это вызывает открытие затвора пушки и разгон ударника.

Испытания на растяжение производятся по схеме Николаса [10]. При этом нагружаемый мерный стержень имеет длину $3 \mathrm{~m}$, а опорный стержень длиной $1.5 \mathrm{~m}$ имеет свободный задний торец. Испытуемые образцы скрепляются со стержнями с помощью резьбового соединения (рис. 1). Импульс растягивающей нагрузки формируется благодаря наличию вокруг образца сплошного или разрезного кольца, которое пропускает через себя практически весь импульс сжатия. В дальнейшем этот импульс сжатия отражается от свободного торца второго стержня волной растяжения и деформирует образец растягивающей нагрузкой.

Экспериментальная установка, описанная выше, позволяет варьировать скорость деформации в широком диапазоне. Для охвата всей области ударники выстреливаются с различными начальными скоростями. Конечной целью применения метода РСГ является динамическая диаграмма $\sigma_{s} \sim \varepsilon_{s}$ с известной историей изменения скорости деформации $\dot{\varepsilon}_{s} \sim \varepsilon_{s}$.

Эрозионные испытания проводились на эрозионной установке аэродинамического типа, схема которой представлена на рис. 2. Частицы ускорялись потоком воздуха до скоростей 40-200 m/s. Испытуемые образцы дистанционно вводятся в рабочую камеру на определенное оператором время. При этом специальный регулируемый дозатор твердой фазы обеспечивает контроль расхода абразивных частиц. Таким образом, используемая экспериментальная установка позволяет регулировать скорость абразивных частиц, их расход и время экспозиции образцов [11].

Образцы изготавливались в виде дисков диаметром $15 \mathrm{~mm}$. Образцы были испытаны при следующих скоростях частиц $-40,80,160$ и $200 \mathrm{~m} / \mathrm{s}$. Для всех испытаний было выбрано фиксированное значение расхода порошка $-4 \mathrm{~g} / \mathrm{s}$. Средний диаметр абразивных частиц 109 и $230 \mu \mathrm{m}$. Испытания проводились при комнатной температуре в течение $5 \mathrm{~min}$.

Результатом проведенных экспериментов являлась шероховатость поверхности. Для определения основных параметров шероховатости поверхности в исследовании

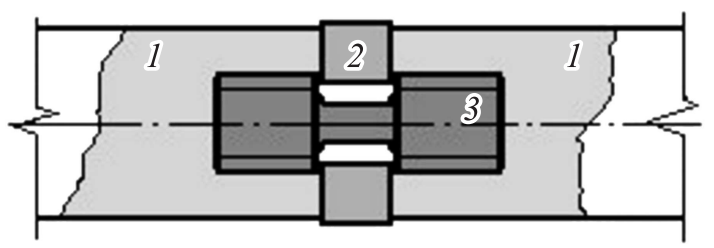

Рис. 1. Схема динамического эксперимента на растяжение. 1 - мерные стержни, 2 - разрезное кольцо, 3 - образец.

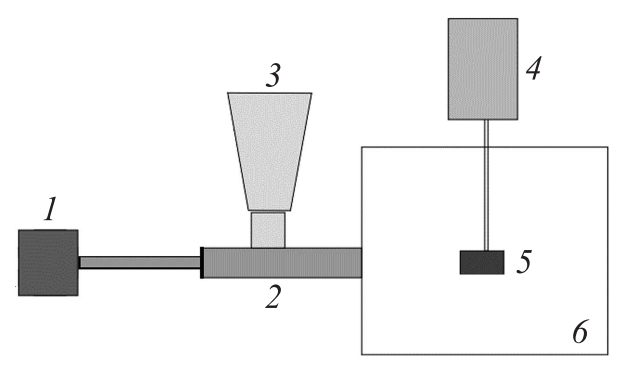

Рис. 2. Схема экспериментальной эрозионной установки аэродинамического типа. 1 - компрессорная камера; $2-$ разгонный участок; 3 - дозатор твердой фазы; $4-$ пневматический привод для ввода образца; 5 - образец; 6 - рабочая камера.

применялся профилометр SJ-210, позволяющий определить среднее отклонение профиля $R_{a}$ (среднего арифметического отклонения всех точек профиля шероховатости от средней линии на длине оценки).

\section{3. Результаты и обсуждение}

Для анализа экспериментальных данных по динамическому растяжению титанового сплава ВТ6, полученных по методике Кольского в научно-исследовательском институте механики Нижегородского государственного университета им. Н.И. Лобачевского, можно воспользоваться критерием инкубационного времени $[12,13]$.

Для хрупкого разрушения критерий инкубационного времени представляется следующим условием

$$
\int_{t-\tau}^{t} \sigma_{r}(v, R, s) d s \leq \sigma_{c} \tau
$$

где $\sigma(t)$ - напряжение растяжения в момент времени $t$; $\sigma_{c}-$ статическая прочность материала; $\tau-$ инкубационное время хрупкого разрушения, являющееся характеристикой динамической прочности материала.

Закон изменения напряжения во времени можно выбрать в виде линейно возрастающей нагрузки, где $\sigma(t)=E \dot{\varepsilon} t H(t), E-$ модуль Юнга, $H(t)-$ функция Хевисайда, $\dot{\varepsilon}$ - скорость деформации. Момент разрушения соответствует наименьшему значению $t^{*}$, при котором условие (1) нарушается. Напряжение, при котором материал разрушается, определяется по формуле

$$
\sigma^{*}=\sigma\left(t^{*}\right) .
$$


На рис. 3 представлена зависимость максимальных растягивающих напряжений от скорости деформации, построенная по критерию (1) при $\tau=0.5 \mu \mathrm{s}$, $\sigma_{c}=1100 \mathrm{MPa}$. Приведенная диаграмма демонстрирует хорошее соответствие теории и экспериментальных данных.

Альтернативный способ тестирования материалов на динамическую прочность может заключаться в оценке поверхности до и после эрозионного воздействия. В качестве параметра эрозионного разрушения была выбрана шероховатость поверхности $\left(R_{a}\right)$. При этом для каждого образца проводилось десять измерений, результирующим значением считалось среднее значение. Основной измеряемой величиной являлось изменение шероховатости поверхности, а именно $\Delta R_{a}=R_{a}-R_{a \text { init }}$, где $R_{a \text { init }}=0.1 \mu \mathrm{m}$ - начальное значение шероховатости образца. Значения $\Delta R_{a}$ для различных скоростей частиц приведены на рис. 4.

Линейная аппроксимация с последующей экстраполяцией результатов для $\Delta R_{a}$ позволила определить пороговые значения для скорости частиц. Пороговым значением скорости абразивных частиц считается величина скорости, превышение которой приводит к изменению

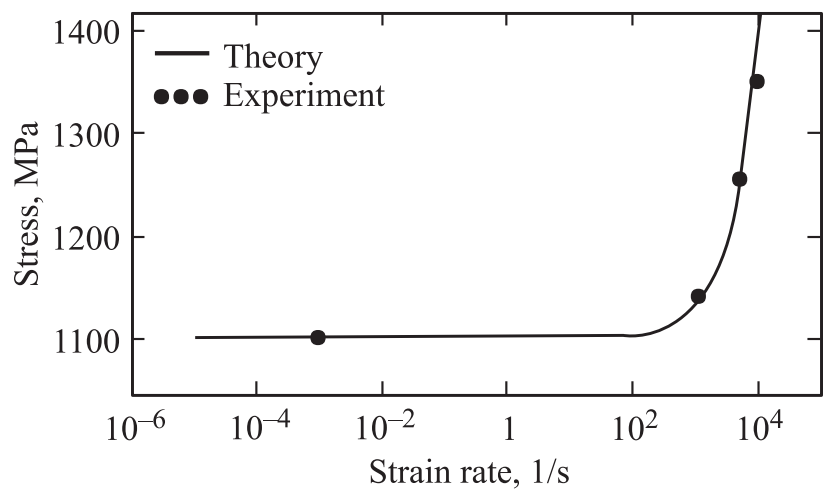

Pис. 3. Зависимость максимальных растягивающих напряжений от скорости деформации. Кривая построена по критерию (1) при $\tau=0.5 \mu \mathrm{s}, \sigma_{c}=1100 \mathrm{MPa}$, точки - экспериментальные данные.

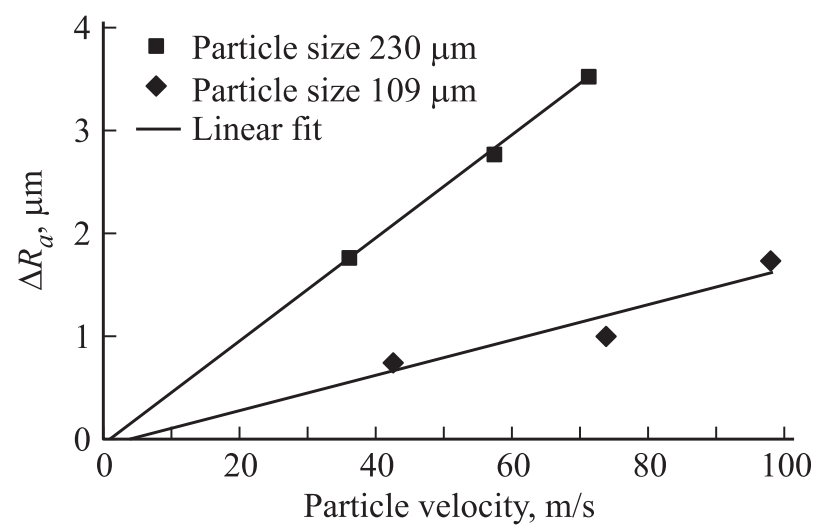

Рис. 4. Зависимость прироста шероховатости поверхности образцов от скорости и размера абразивных частиц.

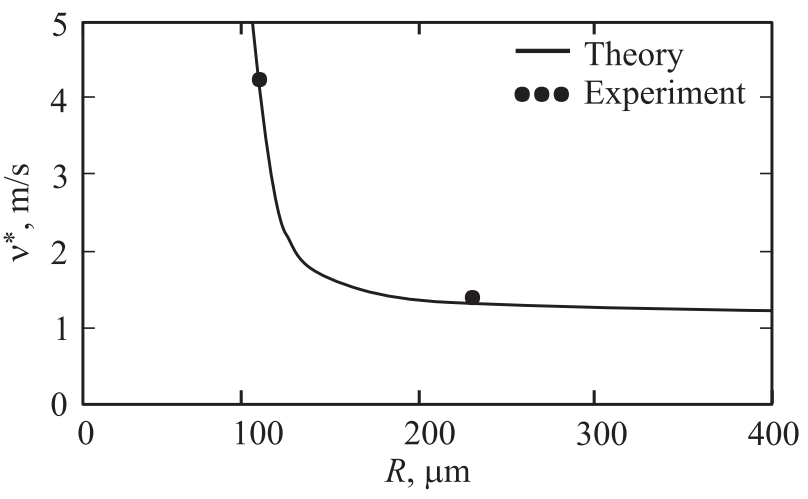

Рис. 5. Зависимость пороговой скорости начала эрозии поверхности образца от радиуса частиц. Кривая построена по критерию (3) при $\tau_{c e}=0.53 \mu \mathrm{s}, \sigma_{c e}=400 \mathrm{MPa}$, точки экспериментальные данные.

шероховатости поверхности образца. Скорости ниже пороговой не приводят ни к каким изменениям поверхности. Полученные пороговые скорости для частиц размерами 109 и $230 \mu \mathrm{m}$ равны соответственно $4.2 \mathrm{~m} / \mathrm{s}$ и $1.4 \mathrm{~m} / \mathrm{s}$.

Проведенные эксперименты показали, что материал имеет различную сопротивляемость поверхности по отношению к высокоскоростному потоку твердых частиц разного размера, производящих кратковременные удары субмикросекундного диапазона длительности. Пороговая скорость для сплава ВТ6 с учетом частиц размером $109 \mu \mathrm{m}$ существенно превышает пороговую скорость для частиц размером $230 \mu \mathrm{m}$. Данная особенность может быть объяснена с использованием критерия инкубационного времени [5,14]. Критериальным соотношением является следующее равенство:

$$
\max _{t} \int_{t-\tau_{e}}^{t} \sigma_{r}(V, R, s) d s=\sigma_{c e} \tau_{e},
$$

где $\sigma_{r}-$ максимальное разрывающее напряжение в точке на поверхности; $V$ - скорость частицы в воздушном потоке; $R$ - радиус частицы; параметры $\sigma_{c e}$ и $\tau_{e}$ относятся к статической и динамической прочности соответственно.

Анализ эрозионного взаимодействия частицы радиуса $R$ и массой $m$ с поверхностью рассматривается по нормали. При этом используются соотношения, полученные при решении задачи Герца $[15,16]$

$$
\begin{gathered}
P(t)=k h^{3 / 2}(t), \\
h(t)=\left(\frac{5}{4 k} m V^{2}\right)^{2 / 5} \sin \left(\frac{\pi t}{t_{0}}\right), \quad t_{0}=3.2\left(\frac{m^{2}}{V k^{2}}\right)^{1 / 5}, \\
\sigma_{r}(t)=\frac{1-2 v}{2} \frac{P(t)}{\pi a^{2}(t)}, \quad a(t)=\left(P(t) \frac{R^{3 / 2}}{k}\right)^{1 / 3} .
\end{gathered}
$$

Здесь $P$ - контактная сила, $h-$ расстояние, на которое может внедриться частица при контакте с по- 
лупространством. Величина $k=4 \sqrt{R} E /\left(3\left(1-v^{2}\right)\right)$, где $v$ - коэффициент Пуассона.

Инкубационное время для титанового сплава ВТ6 можно найти, учтя предельные скорости эрозионного потока и решив уравнение (3) относительно $\tau_{e}$. Подробное описание методики определения параметров материала в рамках критерия инкубационного времени приведено в работе [17]. Определив по предложенному принципу параметры материала, получаем возможность прогнозирования пороговых скоростей потока частиц при разных размерах частиц. На рис. 5 представлена зависимость пороговых скоростей от размера частиц, построенная по критерию (3) с учетом параметров $\tau_{e}=0.53 \mu \mathrm{s}, \sigma_{c e}=400 \mathrm{MPa}$, являющимися параметрами материала. Полученные результаты наглядно демонстрируют эрозионную стойкость материала в широком диапазоне изменения параметров внешнего воздействия. Причем явно выделяются два участка - вертикальный и горизонтальный. Условно, горизонтальный участок кривой зависимости предельной скорости изменения шероховатости поверхности от размера частиц можно назвать статическим, а вертикальный - динамическим. В динамической области материал сопротивляется эрозионному потоку нелинейно, то есть незначительное изменение размера частиц может существенно изменить конечный результат.

Вычисленная величина параметра инкубационного времени при эрозионном процессе разрушения поверхности материала оказалась близкой к величине динамической прочности материала, определенной из экспериментов по высокоскоростному растяжению образцов. Это демонстрирует общую природу откольного и эрозионного разрушения твердых тел, а также открывает дополнительные возможности по получению из экспериментов по высокоскоростному растяжению и эрозии критериальных параметров, необходимых для определения прочностных свойств материалов в широком диапазоне изменения параметров внешнего воздействия.

\section{4. Заключение}

Проведенные эрозионные испытания показали, что титановый сплав ВТ6 имеет различную сопротивляемость поверхности по отношению к высокоскоростному потоку твердых частиц, производящих кратковременные удары субмикросекундного диапазона длительности, в зависимости от их размера.

Данная особенность была проанализирована с использованием критерия инкубационного времени. Полученные результаты показывают, что эффекты откольного и эрозионного разрушения твердых тел имеют общую природу, связанную со спецификой временных процессов при разрушении материалов в условиях динамического нагружения. Важнейшим следствием этой взаимосвязи является возможность извлечения из экспериментов по отколу и эрозии критериальных параметров, необходимых для прогнозирования динамических прочностных свойств материалов. Интересным продолжением данного вывода могло бы стать дальнейшее развитие метода эрозионного воздействия как способа динамического тестирования прочностных свойств материалов.

\section{Список литературы}

[1] H. Kolsky. Proc. Phys. Soc. B 62, 676 (1949).

[2] A.M. Bragov, A.K. Lomunov. Int. J. Impact Eng. 16, 321 (1995).

[3] J.E. Goodwin, W. Sage, G.P. Tilly. Proc. Instit. Mech. Eng. 184, 279, (1969).

[4] Н.А. Казаринов, А.Д. Евстифеев, Ю.В. Петров, В.А. Лашков. ДАН 468, 1, (2016).

[5] Ю.В.Петров, В.И. Смирнов. ЖТФ 80, 2, 71 (2010).

[6] А.Н. Березкин, С.И. Кривошеев, Ю.В. Петров, А.А. Уткин. ДАН 375, 121 (2000).

[7] В.А. Братов, А.А. Груздков, С.И. Кривошеев, Ю.В. Петров. ДАН 396, 345 (2004).

[8] R. Valiev. Nature Mater. 3, 511 (2004).

[9] Q. Wei. Acta Mater. 54, 4079 (2006).

[10] T. Nicholas. Exp. Mech. 21, 177 (1981).

[11] В.А. Лашков. Инж.-физ. журн. 60, 197 (1991).

[12] N.F. Morozov, Y.V. Petrov. Dynamics of Fracture. Springer, Berlin (2000). 99 p.

[13] Y.V. Petrov, N.F. Morozov. ASME J. Appl. Mech. 61, 710 (1994).

[14] Ю.В. Петров, В.И. Смирнов. ДАН 416, 677 (2007).

[15] Ю.В. Колесников, Е.М. Морозов. Механика контактного разрушения. Наука, М. (1989). С. 219.

[16] К. Джонсон. Механика контактного взаимодействия. Наука, М. (1989). С. 510.

[17] Н.А. Горбушин, Г.А. Волков, Ю.В. Петров. ЖТФ 83, 3, 79 (2013). 